\title{
HIPERSENSIBILIDADE RETARDADA A METAIS DE PRÓTESE TOTAL DO JOELHO - UMA REALIDADE A TER EM CONTA
}

\author{
Leonor Ramos', P. Simões², M. Gonçalo ${ }^{3}$ \\ 'Interna de Dermatologia e Venereologia/Resident of Dermatology and Venereology, Serviço de Dermatologia e \\ Venereologia do Centro Hospitalar e Universitário de Coimbra, Portugal \\ IInterno de Ortopedia e Traumatologia/Resident of Orthopedics and Traumatology, Serviço de Ortopedia e \\ Traumatologia do Centro Hospitalar e Universitário de Coimbra, Portugal \\ ${ }^{3}$ Assistente Graduada Sénior, Chefe de Serviço, Assistente Convidada da Faculdade de Medicina da Universidade de \\ Coimbra/Consultant Chief, Invited Professor of the Medical School of Coimbra University, Portugal
}

RESUMO - As reacções de hipersensibilidade retardada (HSR) a metais em doentes com próteses ortopédicas podem causar lesões cutâneas e/ou inflamação dos tecidos peri-protésicos com dor e/ou compromisso funcional da prótese. Muitos destes sinais são comuns à infecção peri-protética o que coloca importantes dificuldades no diagnóstico diferencial deste problema crescente. Uma doente do sexo feminino, 7 meses após artroplastia total do joelho (ATJ) desenvolveu dor e limitação funcional com derrame peri-articular e placa inflamatória em redor da cicatriz com nódulo que drenava material sero-sanguinolento. As culturas deste material e de líquido articular, obtido por artrocentese, foram repetidamente negativas e não se observou melhoria com múltiplos antibióticos usados de forma empírica, afastando a hipótese de infecção da prótese. Foram então realizados testes epicutâneos que revelaram reacções positivas ao dicromato de potássio $0.5 \%$ vas e óxido de titânio $0.5 \%$ pet, presentes na liga metálica da prótese, o que pode explicar a sintomatologia apresentada.

Apesar de não estar estabelecida de forma definitiva a importância da relação entre a sensibilidade cutânea a metais e as reacções de hipersensibilidade peri-implante com a consequente falência de implantes protéticos, esta possibilidade deve ser evocada perante lesões cutâneas junto ao local de implantação de próteses.

PALAVRAS-CHAVE - Artroplastia do joelho/efeitos adversos; Hipersensibilidade retardada; Metais; Próteses do joeIho; Testes epicutâneos.

\section{DELAYED HYPERSENSITIVITY TO METALS IN TOTAL KNEE PROSTHESIS - A REALITY TO KEEP IN MIND}

ABSTRACT - Delayed-type hypersensitivity to metals in patients with orthopedic implants may cause cutaneous lesions and/or pain, effusion and functional impairment of the prosthesis. As these signs are common to periprosthetic joint infection, the differential diagnosis is difficult, but metal hypersensitivity has to be considered as a possible cause of this growing problem. Seven months after total knee arthroplasty, a female patient developed pain and functional impairment of the knee, cutaneous erythema, swelling and a nodule with serous-hematic drainage in the inferior limit of the surgical scar. Microbiologic study was repeatedly negative. Patch testing showed reactivity to chromium (potassium dichromate $0.5 \%$ pet), a constituent of the metallic prosthesis, and also to titanium oxide $0.5 \%$ pet, neomycin $20 \%$ pet and gentamicin $20 \%$ pet, which might explain the inflammatory reaction surrounding the prosthesis.

Although rare, there is an association between metal hypersensitivity and implant failure. Therefore, in the presence of skin lesions around the prosthesis implantation site, metal hypersensitivity should be considered and studied.

KEY WORDS - Arthroplasty, Replacement, knee/adverse effects; Hypersensitivity, delayed; Knee prosthesis; Metals; Patch tests.

Conflitos de interesse: Os autores declaram não possuir conflitos de interesse.

No conflicts of interest.

Suporte financeiro: $O$ presente trabalho não foi suportado por nenhum subsídio ou bolsa.

No sponsorship or scholarship granted. 


\begin{abstract}
Direito à privacidade e consentimento escrito / Privacy policy and informed consent: Os autores declaram que pediram consentimento ao doente para usar as imagens no artigo. The authors declare that the patient gave written informed consent for the use of its photos in this article.
\end{abstract}

Recebido/Received - Janeiro/January 2015; Aceite/Accepted - Março/March 2015

\title{
Correspondêncio \\ Dr.. Leonor Ramos
}

Serviço de Dermatologia e Venereologia

Centro Hospitalar e Universitário de Coimbra

Praceta Mota Pinto - 3000 Coimbra, Portugal

Email: leonoricr@gmail.com

\section{INTRODUÇÃO}

A hipersensibilidade retardada (HSR) ou hipersensibilidade do tipo IV mediada por linfócitos T e dirigida a metais, além da dermatite de contacto alérgica (DCA) que ocorre após exposição cutânea, pode ocasionar manifestações clínicas em órgãos internos onde há contacto com dispositivos metálicos, tais como implantes ortopédicos, clips cirúrgicos, implantes dentários e stents cardiovasculares, afectando o sucesso destas. ${ }^{1}$

Na maioria dos doentes em que são colocadas próteses metálicas ortopédicas não existe qualquer reacção por parte do sistema imune. No entanto, supõe-se que os metais em contacto com os sistemas biológicos sofram corrosão, com consequente libertação de iões metálicos e sais insolúveis que se fixam a proteínas tecidulares podendo induzir sensibilização ou causar reacção inflamatória do tipo da HSR em indivíduos previamente sensibilizados. ' Esta reacção é habitualmente localizada e manifesta-se por lesões eczematosas peri-articulares. No entanto, as lesões podem generalizar e manifestar-se como eczema, urticária e vasculite. Deste modo, se surgirem lesões cutâneas junto do local de implantação de prótese algum tempo após a colocação da prótese, o diagnóstico de reacção de HSR deverá ser sempre equacionado.

Não existe, contudo, de momento, um teste unanimemente aceite para a avaliação de HSR a materiais implantados.'

Os autores descrevem o caso de uma doente com reacção cutânea inflamatória suprajacente à cicatriz de prótese total do joelho, em provável relação com hipersensibilidade ao metal contido no implante.

\section{CASO CLÍNICO}

Uma doente de 56 anos de idade foi enviada à consulta de Alergologia de Contacto para realização de testes epicutâneos (TE) para estudo de inflamação cutânea e derrame articular, com dor e limitação funcional do joelho direito com duração de 3 meses. As queixas tinham surgido 7 meses após colocação de prótese total do joelho (PTJ) por pangonartrose.

À observação era notória uma placa cutânea inflamatória da região do joelho direito, sobretudo em redor da cicatriz cirúrgica e um nódulo de cerca de $2 \mathrm{~cm}$ na extremidade inferior da cicatriz no 1/3 superior da perna, que drenava conteúdo sero-hemático (Fig. 1).

Os exames microbiológicos do exsudato e de artrocentese revelaram-se repetidamente negativos e não houve benefício com múltiplos tratamentos antibióticos usados de forma empírica. Do ponto de vista analítico não havia leucocitose (leucócitos $5.4 \mathrm{G} / \mathrm{L}$ ), verificando-se uma PCR de $2.42 \mathrm{mg} / \mathrm{dl}(\mathrm{N}<1 \mathrm{mg} / \mathrm{dl})$. Radiologicamente não eram aparentes sinais de descolamento da prótese, mau posicionamento ou sinais de osteólise em redor da prótese.

Foram realizados TE com a Série Básica, (meta)acrilatos, metais e medicamentos tópicos (Chemotechnique Diagnostics ${ }^{\circledR}$, Vellinge, Sweden) de acordo com as recomendações internacionais. Foram colocados cerca de 20 mg de cada alergeno em Finn Chambers $^{\circledR}$ de $8 \mathrm{~mm}$

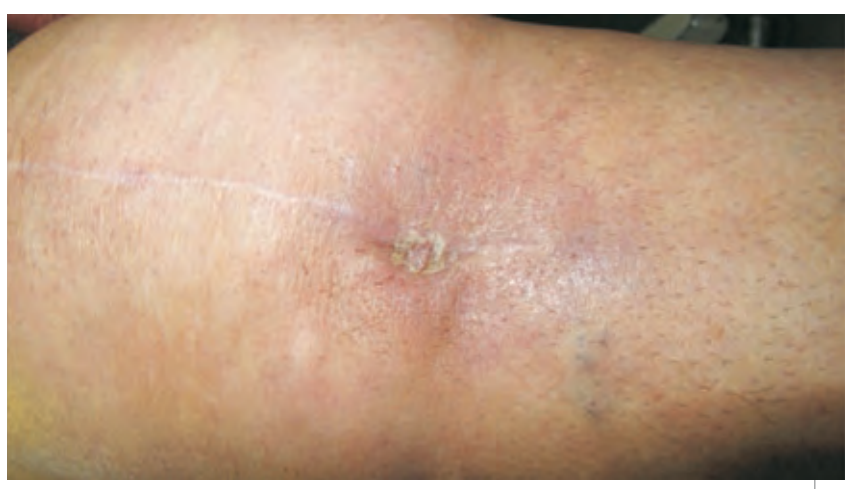

Fig 1 - Placa inflamatória da face anterior do joelho sobre cicatriz de anterior PTJ, com nódulo que drenava material sero-hemático, antes e depois da aplicação de dermocorticoide. 
que foram aplicados de imediato na metade superior do dorso e deixados em oclusão durante $48 \mathrm{~h}$. As leituras foram efectuadas ao fim de 2 e 3 dias, de acordo com as normas do International Contact Dermatitis Research Group (ICDRG) que classifica as reacções em fraco $(+)$, forte $(++)$ e extremo $(+++)$ consoante a sua morfologia. Verificou-se reactividade ao crómio (dicromato de potássio $0.5 \%$ vas) $(++/+)$, óxido de titânio $5 \%$ vas $(+/+?)$, neomicina $20 \%$ vas $(++/++)$ e gentamicina $20 \%(+/+)$ (Fig. 2).

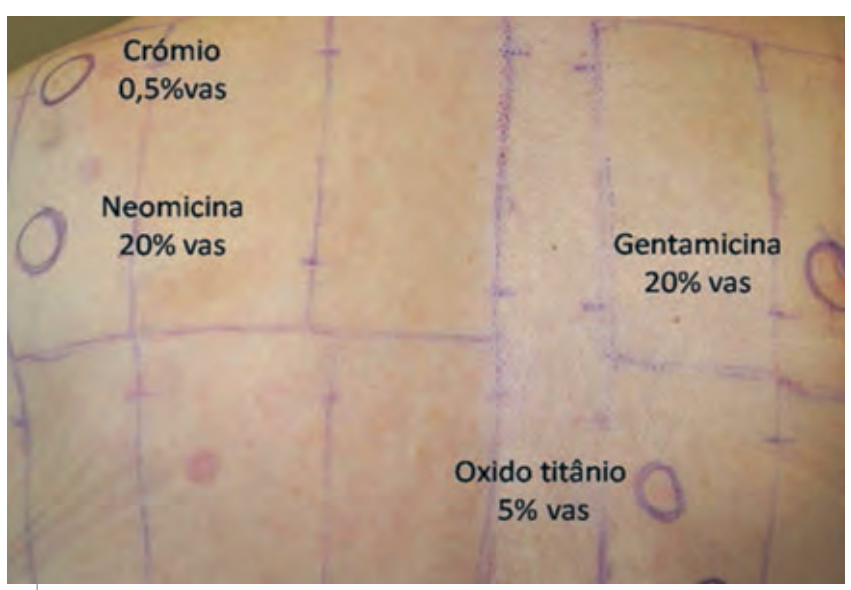

Fig 2 - tado dos TE com positividade ao crómio 0,5\% vas e óxido de titânio $5 \%$ vas.

Apesar de a gentamicina ser ocasionalmente incluída profilacticamente no cimento de fixação da prótese, tal não aconteceu neste caso. A prótese era constituída por uma liga metálica constituída por crómio-cobalto (Legacy $^{\circledR}$ Knee LPS-Flex, Zimmer ${ }^{\circledR}$ ), o que poderá explicar a reactividade ao crómio observada no TE e a reacção inflamatória observada na pele sobrejacente à aplicação do material metálico. Esta paciente negava outras fontes de sensibilização ao crómio ou DCA noutras localizações.

A doente foi medicada com dermocorticóide e mantém seguimento em consulta de Ortopedia. Optou-se por se remover a PTJ pela manutenção das queixas, apesar do encerramento do orifício de drenagem. Aguarda colocação de prótese biocompatível.

\section{DISCUSSÃO}

Apesar de raramente descrito, existe associação entre hipersensibilidade de contacto a metais e reacções de hipersensibilidade peri-implante com inflamação, por vezes "descolamento" e consequente falência da prótese ortopédica.
Múltiplos metais que entram na composição das próteses ortopédicas são sensibilizantes conhecidos: níquel, cobalto, crómio, embora também já tenham sido descritas reacções ao titânio, vanádio e tântalo.' $\mathrm{O}$ níquel é o alergeno mais frequentemente encontrado, tanto na população normal como nos doentes estudados por patologia cutânea, seguido do paládio, cobalto e do crómio. ${ }^{2}$

As ligas metálicas utilizadas nas próteses de ortopedia são variadas, sendo as mais frequentes mistura de níquel, crómio e molibdénio ("stainless steel"); níquel, cobalto, crómio e molibdénio ("cobalt alloy"); titânio, alumínio e valádio ("titanium alloy") ou cobalto, crómio e molibdénio ("vitallium alloy").1,3 Realça-se que a reacção de HS não é à prótese em si mesma, mas sim aos produtos de corrosão e dissolução libertados para os tecidos adjacentes devido ao uso a que a prótese é sistematicamente sujeita.

A maioria dos casos descritos ocorreu essencialmente em doentes com próteses compostas por ligas metálicas stainless-steel e ligas de cobalto, sendo mais raras (apesar de também descritas) nas ligas de titânio. ${ }^{1,4}$ No entanto, a maioria dos indivíduos com TE positivos a metais tolera as próteses metálicas: cerca de $25 \%$ dos doentes com próteses funcionantes estão sensibilizados, com TE positivos, apesar de clinicamente assintomáticos. ${ }^{1,5}$ Nos doentes com falha da prótese ortopédica, a prevalência de TE positivos a metais sobe para $60 \%$, uma percentagem significativamente mais elevada do que a encontrada na população geral. ${ }^{5}$ No entanto, é ainda controverso se é a sensibilidade ao metal que conduz à instabilidade da prótese ou o inverso, com a instabilidade gerando inflamação que favorece a sensibilização ao metal. ${ }^{1,4}$

As manifestações cutâneas podem ser diversas, variando de eczema localizado, a urticária, lesões boIhosas, vasculite e alterações de cicatrização sobre a localização dos implantes, e podem estar associadas, ou não, a queixas álgicas, derrame articular, incapacidade funcional e descolamento protético. As manifestações cutâneas podem ser localizadas à área peri-protética ou generalizadas. ${ }^{1,3,5}$

Os TE, fundamentais no diagnóstico de DCA, têm eficácia menor na identificação destas reacções de hipersensibilidade a metais. É habitualmente difícil fazer uma correlação positiva entre TE positivos e as reacções inflamatórias que surgem em torno da prótese. Não obstante, a reactividade ao crómio e ao cobalto, presentes na liga metálica usada nas próteses ortopédicas, pode, de facto, explicar as reacções inflamatórias cutâneas em que a causa infecciosa foi excluída.

Para alguns metais como o titânio, paládio, manganésio e outros mais recentemente incluídos em próteses (zircónio e tântalo) não foi ainda definido qual o melhor 
sal, veículo e concentração para efectuar o TE de forma a obter um resultado mais sensível e específico na detecção de reacções cutâneas de HS retardada a estes metais. Os alergenos de metais actualmente comercializados não causam falsas reacções positivas na nossa experiência, mas poderão ser muitos os resultados falsamente negativos.

Existem actualmente testes in vitro de transformação linfocitária (LTT), testes de inibição da migração leucocitária (LIF) ou testes de ELISA (ELISpot) para determinação de hipersensibilidade a metais, baseados na migração e proliferação linfocitária ou produção de citocinas quando na presença do metal específico. ${ }^{5}$ Os LTT, embora defendidos por alguns como testes seguros e fiáveis, ${ }^{1}$ apresentam algumas limitações, tendo mostrado baixa especificidade e sensibilidade, com estimulação linfocitária a ocorrer nos indivíduos controlo e em indivíduos com prótese mas sem sintomatologia. 5,6 Têm elevados custos e há limitação do número de metais que se podem testar. ${ }^{5} \mathrm{O}$ ELISpot, que mede por técnicas de ELISA a produção de citocinas (IFN- $\gamma$ ou outras) pelos linfócitos $T$ específicos do metal, tem mostrado grande variabilidade em realizações sucessivas o que questiona também a sua sensibilidade e especificidade. Estes testes in vitro podem, no entanto, ser úteis para comprovar algumas dúvidas diagnósticas.

A biópsia do tecido peri-protético, que habitualmente mostra infiltrado difuso e perivascular de linfócitos e plasmócitos e reacção fagocitária, é um importante elemento para reforçar o diagnóstico de reacção de hipersensibilidade, ${ }^{7}$ mas não foi efectuada no nosso caso.

Após a confirmação de HSR ao metal da prótese nestes pacientes, não existem outras alternativas terapêuticas além de cirurgia de revisão e remoção do material implantado. No entanto, mesmo perante um TE positivo, se a prótese estiver funcionante e não houver queixas álgicas ou descolamentos, não se deverá proceder a qualquer remoção de material. ${ }^{3}$

Assim, e apesar de ainda não existirem preparações estandardizadas para testar outros metais além de crómio, cobalto, paládio e níquel, recomenda-se a realização de TE a doentes com reacções adversas a próteses ortopédicas, mesmo na ausência de lesões cutâneas. Os TE, além de diagnósticos, podem orientar a selecção de material de futura prótese, caso esta venha a ser necessária.

A realização de TE de forma rotineira para determinação de sensibilização a metais não é recomendada antes da colocação da primeira prótese, iá que não há dados que permitam prever se o risco de complicações ortopédicas em doentes com TE positivos é superior aos indivíduos com TE negativos. ${ }^{5}$ No entanto, se existir história pregressa forte que sugira intolerância a metais, estes deverão ser realizados. ${ }^{3,5}$

\section{CONCLUSÕES}

Perante um doente que desenvolve reacção cutânea inflamatória meses ou anos depois de aplicação de prótese ortopédica, deverão ser efectuados TE com uma série apropriada de metais. Os testes in vitro pela sua baixa sensibilidade e especificidade não constituem diagnóstico de primeira linha. Se houver reactividade relevante e a clínica não for controlada com dermocorticóide, deverá ser considerada a remoção e substituição do material protésico por outro isento dos metais a que se verificou a reactividade. ${ }^{3,5}$

\section{REFERÊNCIAS}

1. Hallab N, Merritt K, Jacobs J. Metal sensitivity in patients with orthopaedic implants. J Bone Joint Surg. 2002; 83:428-36.

2. Teixeira V, Coutinho I, Gonçalo M. Alergia de contacto a metais num período de 20 anos no centro de Portugal: implicações das directivas europeias. Acta Méd Port. 2014: 27: 295-303.

3. Basko-Plluska J, Thyssen J, Schalock P. Cutaneous and systemic hypersensitivity reactions to metallic implants. Dermatitis. 2011; 22:65-79.

4. Krecisz B, Kieć-Šwierczynska M, Bakowicz-Mitura K. Allergy to metals as a cause of orthopedic implant failure. Int J Occup Med Environ Health 2006; 19:178-80.

5. Thyssen JP, Menné T, Schalock PC, Taylor JS, Maibach HI. Pragmatic approach to the clinical work-up of patients with putative allergic disease to metallic orthopaedic implants before and after surgery. Br J Dermatol.2011; 164:473-8.

6. Hallab N, Caicedo M, Finnegan A, Jacobs J. Th 1 type lymphocyte reactivity to metals in patients with total hip arthroplasty. J Orthop Sur Res. 2008; 3:6.

7. Thomas P, Braathen LR, Dörig M, Auböck J, Nestle $\mathrm{F}$, Werfel $\mathrm{T}$, et al. Increased metal allergy in patients with failed metal-on-metal hip arthroplasty and peri-implant T-lymphocytic inflammation. Allergy. 2009; 64:1157-65 